\title{
360-Degree Videos, VR Experiences and the Application of Education 4.0 Technologies in Malaysia for Exposure and Immersion
}

\author{
Airil Haimi Mohd Adnan*, ${ }^{*}$, Mohamad Syafiq Ya Shak ${ }^{1}$, Rafidah Abd Karim², Mohd Haniff Mohd Tahir ${ }^{1}$, Dianna Suzieanna M Shah ${ }^{1}$ \\ ${ }^{1}$ Universiti Teknologi MARA Perak Branch (UiTM), Seri Iskandar Campus, Perak, 32610, Malaysia \\ ${ }^{2}$ Universiti Teknologi MARA Perak Branch (UiTM), Tapah Campus, Perak, 35400, Malaysia
}

\author{
A R T I C L E I N F O \\ Article history: \\ Received: 01 January, 2020 \\ Accepted: 28 January, 2020 \\ Online: 07 February, 2020
}

\begin{abstract}
A B S T R A C T
Obstacles, both imagined and real, continue to hinder the wider adoption of Education 4.0 learning technologies although these technologies are available in the mainstream consumer market. At the same time, the boom in Industry 4.0 manufacturing has brought down the prices of these technological tools making them generally more affordable. A case in point is 360-degree spherical video cameras and software that can record, render and playback immersive 'real life' contents. 360-degree spherical video contents can then be rendered and post-processed into VR (virtual reality) experiences that are not just immersive but also allow for limitless exposure time to learners. Both technologies allow for learner-driven learning to happen in the truest sense, for instance for second and foreign language learners. This research paper examines data collected from 560 undergraduates $(n=560)$ who were immersed and exposed to 360-degree videos and VR experiences for degree level courses on English (as a second language), Mandarin (Chinese) (as a third or foreign language, and Arabic (as a third or foreign language) at four public university campuses in Peninsular Malaysia. The benefits of 360-degree videos and VR experiences in second and foreign languages content delivery were evident to support learner-driven learning: Contents were developed by local lecturers and then uploaded for free online and learners could learn anytime, anywhere; total immersion could be achieved using cheap VR goggles powered by learners' smartphones; and most beneficially, weaker learners who desperately need more time to understand and practice difficult degree level second or foreign languages now have the freedom to revise and upskill themselves at their own pace.
\end{abstract}

\section{Introduction}

The leading futurist Gerd Leonhard [1] predicts that human civilisation will see more changes in the next 20 years than we have ever experienced in the last 300 . If this prediction comes true, then those who are able to 'see' these changes before they happen and those who are responding in an active manner will have a lead over others who are merely reacting to those changes after they have happened. Indeed, there are changes happening now that are revolutionising the jobs that we do and the ways that we learn. Driven by technical developments never witnessed before, the nature of modern living as we know it will never be the same [2].

Within the realm of formal education, rapid changes are also happening. We have reached a critical juncture in teaching and

${ }^{*}$ Corresponding Author: Dr. Airil Haimi Mohd Adnan, admin@uforia.edu.my www.astesj.com

https://dx.doi.org/10.25046/aj050148 learning because of Industry 4.0 disruptions [3, 4]. Within this context, educators and learners need to change the way they think and perceive the world from "Why should we be doing this?" to "Why aren't we doing this?" [5,6]. One of the momentous changes happening right now within education is the convergence of technologically-enhanced immersive learning with learner exposure and learner-driven learning. These three concepts might be different, but they relate to the same key purpose which is to help our learners to learn in a more engaging, productive and useful manner compared to just learning by rote and memorising disjointed facts and figures that are easily forgotten [7]. Within the wider umbrella of immersive learning initiatives, learners at all stages of formal education in developed and developing nations are being exposed to interactive environments both physically and virtually; these are environments that can reproduce real world 
scenarios to teach certain skills. Combining simulations, game elements and virtual environments, 'true' immersive learning is finally made possible with technological developments from Industry 4.0 and supported by the philosophies of the Education 4.0 global movement [8].

\section{Review of Research Literature}

In this section, research literature that relates to the empirical inquiry reported in this paper is reviewed starting with an in-depth discussion of the notion of immersive learning followed by 360degree videos and virtual reality (VR) experiences within the realm of education. The discussion is framed within the broader picture of the Industry 4.0 era and Education 4.0 universal movement.

\subsection{Immersion, exposure and learner-driven learning}

Within the realms of education and training, new and affordable Industry 4.0 technologies are creating new ways to make immersive learning more experiential and learner driven whilst opening opportunities to 'transport' learners into controlled environments with engaging tasks or situations for them to engage in. Figure 1 depicts the movement from less interactive learning materials to more immersive learning materials. The direct result of this is the ability of learners to learn at such a great depth than previously thought possible. As learning technologies start to quickly bridge the gap between what is conceivable and what is practical, deeply immersive learning is now feasible and it will continue to deliver more memorable and meaningful learning 'experiences' in future [1].

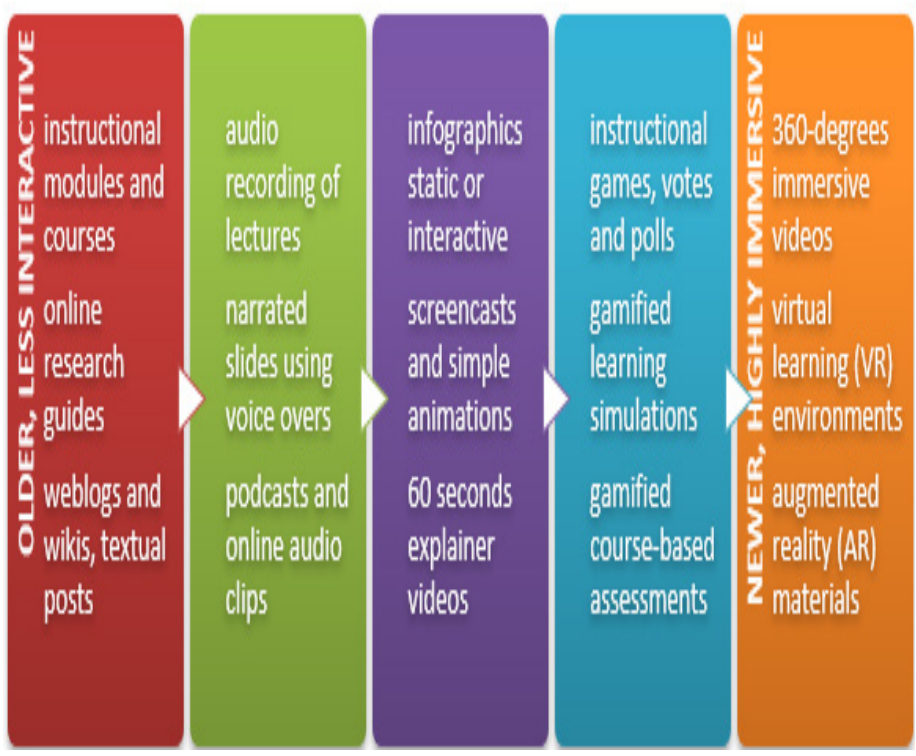

Figure 1: Digital learning objects from older and less interactive to newer and highly immersive ones

At tertiary level, to create an immersive learning experience traditionally might be limited to the course instructor telling a story or role playing a situation with learners [9]. For university or college instructors with more resources and time, instructional videos or online learning games offer some sort of immersion by drawing on experiences that emulate real-life situations and enable practice to happen in real time. Indeed, research suggests that experiences gained during learning simulations can be stored in our memory as if they were real [10]. At the same time, there are limitations with these approaches $[11,12]$.

Traditional flat 2D video clips and online learning games for example are limited in their learning value. Plus, they are far from immersive though they might be somewhat interactive. Worse, some learners can finish watching them or playing them quickly, lessening exposure time that is desperately needed by weaker learners to learn and relearn skills that might be difficult for them. At the other end of the spectrum, 'true' immersion that combines the best of e-Learning with engaging simulations is highly complex to produce and will therefore come at a higher price tag. Unsurprisingly, even for universities and colleges with a lot of cash, the price factor is always a burden in learning content development and deployment, not just in developing countries but in developed ones as well [13].

\subsection{Learning through 360-degree videos and virtual reality (VR) experiences}

Thankfully, rapid technical and technological developments of Industry 4.0 manufacturing have led to the creation of a new generation of immersive learning technologies that can be fully utilised by university or college instructors [14]. These include interactive 360-degree video technology, virtual reality or VR experiences, augmented reality or AR overlays, and mixed reality (MR) or extended reality (XR) simulations. Together, these technological tools hold exciting possibilities for bringing an immersive and learner-driven learning experience into the lecture room.

360-degree videos enable learners to observe a scene in whichever direction they wish. Thus, they are able to virtually explore a made up world or view an actual recording of the real world made by 360-degree video cameras. On smartphones, as learners move and turn their devices left and right or up and down, the images that they see move in perfect synchrony; on laptops computers and desktops, they can easily navigate spherical 360degree videos by clicking and dragging navigation buttons. YouTube, for example, is witnessing a great number of 360-degree videos being uploaded not just for entertainment but also for teaching and learning purposes. On newer platforms like VeeR (which markets itself as the 'YouTube for VR') and using more advanced commercially-available software, 360-degree videos can be further rendered and post-processed into standalone 'virtual reality experiences'. VR experiences represent the cutting edge of technologically-enhanced teaching and learning, and they can be powered by standalone VR headsets capable of immersing and exposing learners to new learning experiences $[15,16]$.

With reference to VR experiences, whether they are fully computer-generated environments or built upon 360-degree videos from real-life situations, these experiences lead to immersive learning and longer exposure time for learners without real life difficulties, even though the initial setup will need investments to defray high costs. VR experiences enable learners to learn firsthand from their mistakes. And, it allows for longer exposure to learning materials and more practice time, especially for weaker learners who might have difficulties to acquire specific skills and knowledge from the classroom time alone. Immersing learners in real-life situations using interactive VR experiences is especially useful to train and develop soft skills, second language and also 
third language skills [17]. Other skills like customer services or people management and formal meeting or negotiations are great examples where learners can be placed in positions of potential tension but where they are able to 'see' how certain decisions will lead to certain outcomes, without risks.

By learning about workplace-related scenarios in an interactive VR environment, for instance, the learner will be able to develop appropriate workplace-related skills to resolve conflicts, dilemmas, and problems in an appropriate manner. In other words, this really is learning by doing in the truest sense of the term. This is due to the fact that we have reached an exhilarating point in the rise of immersive learning technologies, as several factors converge to transform the future of learning landscape [18]. VR technology has now evolved from a personal computer tethered technology to one that can be easily accessed using smartphones and tablets. At this moment in time, an immersive VR experience is attainable merely by using the same gadgets that we carry in our pockets and bags. Furthermore, thanks to current VR platforms like VeeR, there is no need for special apps to be installed on smartphones. Add to this the wider affordability of cheap and easy to use smartphone-powered VR headsets (compared to 5-10 years ago), the investment needed to access immersive VR experiences is becoming lower all the time for learners at all levels of formal education.

\subsection{0-degree videos and virtual reality (VR) experiences for Education 4.0}

The global Education 4.0 movement should be viewed as a set of trends and challenges that tertiary educators need to be aware of and to respond to (see Times Higher Education, 2019). The first trend is the transformation of the teaching and learning process. Tertiary educators must reconsider why and how they teach once Artificial Intelligence (AI) and other deep learning technologies become more prevalent in colleges and universities. The second trend is more personalised learner-driven learning. Tertiary educators must be able to cater to the learning styles of students and consider their individual behaviours, differences and performances. The next trend is personalised assessment. As AI systems run classroom tests, experiential learning through digital technologies will become the norm, so tertiary educators need to do without the high-stakes pen and paper tests. The final trend is the growth in intelligent digital environments. As digital environments become more common in physical classrooms, tertiary students need better experiences to be able to interact effectively and learn from and within those environments [19].

Today, the technological tools, software and apps related to Education 4.0 and Industry 4.0 that are needed to produce VR experiences are becoming more affordable and more accessible with newer and cheaper 360-degree cameras arriving on the commercial market [20]. Fully digital VR worlds could also be designed and built, albeit with technical know-how and a lot of time at hand. Consequently, the stage is set for immersive learning that is fully driven by learners to enter the learning ecosystem in formal education [21, 22]. Figure 2 illustrates VR technologies in education that are currently available for teaching and learning.

Still, there are issues and problems to contend with before these disruptive Education 4.0 technologies could spread from technically-savvy content developers to mainstream adoption [23].
The question is not whether something is new, but rather will it be better than what we have had in the past? [24, 25]. This is where hard evidence needs to be collected and analysed to truly examine whether immersive VR experiences are better for teaching and learning, in the tertiary education sector especially, compared to the teaching and learning methods that we have had in the past like 'chalk and talk' and rote learning that are supported by regimented drills and repetition exercises [26]. To answer these and other pertinent questions related to immersion, exposure and learnerdriven learning through 360-degree videos and VR experiences, an empirical inquiry was carried out as explained in the next section.

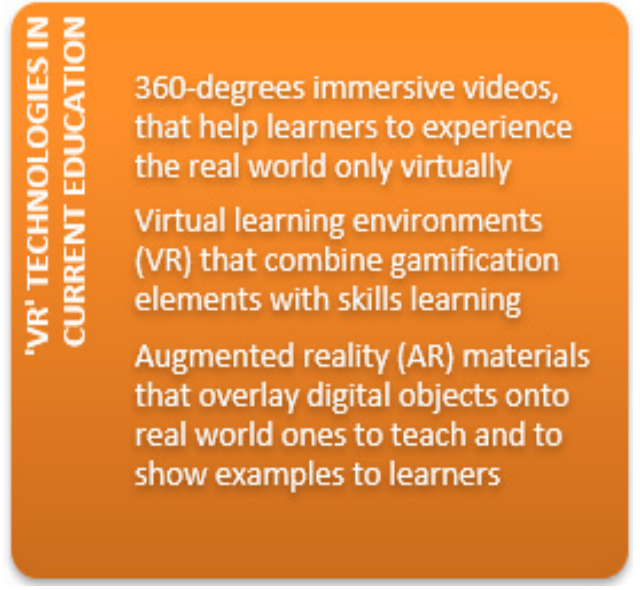

Figure 2: VR technologies that are currently available in education

\section{Research Methods and Research Participants}

This study examines quantitative and qualitative data collected from 560 undergraduates $(\mathrm{N}=560)$ who were immersed in, and exposed to, 360-degree videos and VR experiences for several degree level courses on English Language (second language), Mandarin Chinese (third/foreign language), and Arabic Language (third/foreign language) at four public university campuses in northern Peninsular Malaysia. 357 of the undergraduates are female and the other 203 are male; 136 of them were doing first degrees in art and design, and other architecture, planning or surveying-related courses, whereas the other 424 were first degree students in science and technology courses including engineering, computer sciences, applied sciences and other related courses. Overall, the data collection and analysis process took about ten months to complete, spanning two semesters, from the start of 2019. In particular, the study sets out to find answers to three research questions (RQ):

RQ1: What are the advantages and disadvantages of 360 degree videos and VR experiences in delivering educational materials, specifically for tertiary level second and third (foreign) language courses?

RQ2: Compared to methods used by 'traditional' instructors, how useful are 360-degree videos and VR experiences, for the current generation of undergraduates who are studying second and third (foreign) language courses?

RQ3: In the future, will 360-degree videos and VR experiences become more common as part of immersive and interactive learning initiatives, not just for the teaching of second and third (foreign) language courses? Why? 


\subsection{Research instruments and research cycles}

In Cycle One of the studies, quantitative data collection was done using an online survey questionnaire with 25 items that asked the respondents to compare between 360-degree video materials and VR experiences with traditional learning in terms of their usefulness, usability and overall impression. They were also asked to respond to items related to the future of 360-degree videos and VR experiences, and the strength and weaknesses of these technologies with regards to language teaching and learning (both for second and third or foreign languages). Additionally, they were asked to respond to some survey items that are related to the contribution of 360-degree videos and VR experiences to their abilities and skills in either the English Language, Mandarin Chinese, or Arabic Language.

This was followed by Cycle Two that involved the collection of qualitative data employing focus group discussion sessions. These sessions were tied in with post-evaluation sessions during the actual class time to address the actual performances of the students involved in the three language courses. Five open questions were posed to a group of four to five learners regarding the same subject matters covered in Cycle One. The students (participants) were free to share their own ideas, feelings and opinions regarding the teaching and learning of either the English Language, Mandarin Chinese, or Arabic Language employing the 360-degree videos and VR experiences.

\subsection{Data management and data analysis}

The data collected from Cycle One were analysed based on mean, mode and median frequencies. The analysis of the data was done to show the prevalence of certain criteria based on the experiences of the respondents, for instance: the usefulness and usability of 360-degree videos and VR experiences; the perceived future of 360-degree videos and VR experiences; the strengths and weaknesses of these technologies with reference to second and third language education; and the influence of 360-degree videos and VR experiences on the abilities and skills of the respondents with regards to specific English Language, Mandarin Chinese, and/or Arabic Language skills.

The data collected from Cycle Two were more substantial and 'thick' [27] given the fact that the participants were asked to share their ideas, feelings and opinions in an open manner amongst their peers. Other than selective transcriptions of the focus group data, the participants were also requested to write a summary of the points and ideas that they talked about during the session. These were then checked and reshared with the participants to allow for 'member checking' [28] to happen. No clear-cut protocols were prepared for the discussion sessions and only open questions were posed to allow the participants to make comments and share their experiences freely. Sessions were conducted fully in either English or Malay language, as the national language of Malaysia (particularly for the Mandarin Chinese and Arabic Language undergraduate students).

After transcribing and coding, the data were thematically analysed in two stages: horizontal (group data) and vertical (personal data). At the end of the data collection and analysis stage, the three research questions were answered satisfactorily.

\section{Research Results and Discussion}

The results of this study are divided into two subsections as seen below: Cycle One and Cycle Two. The data for Cycle One are numerical/quantitative whereas the data for Cycle Two are textual/qualitative. Salient data are presented in this section and critically discussed, in an attempt to address three research/guiding questions in this empirical effort.

\subsection{Cycle 1: Numerical/quantitative data}

560 undergraduates (i.e., survey respondents) completed a 25 item survey questionnaire online where they were asked to compare 360-degree video materials and VR experiences with more traditional learning methods. They were also asked to think about the future of 360-degree video materials and VR experiences in tertiary education, and to gauge how these learning technologies have influenced their specific second or third language abilities and skills (in the English Language, Mandarin Chinese, or Arabic Language).

Using a Likert scale, the respondents were able to choose between 'Strongly disagree', 'Disagree' or 'Fairly disagree' at the negative end of the spectrum whilst at the positive end they could choose either 'Fairly agree', 'Agree' or 'Strongly agree'. Neutral or unsure responses were not included as these are typical distractors that student-respondents will normally choose, based on our personal experience in doing such research.

The first item in the online survey questionnaire asks the respondents whether the use of 360-degree videos and VR experiences felt more useful to them compared to more traditional teaching methods like chalk and talk, drilling and also lecturing. Perhaps unsurprisingly and given the fact that the respondents have all been exposed to 360-degree videos and VR experiences to some degree beforehand, 511 or $91.25 \%$ of them chose positive answers, as seen in Graph 1 below.

Graph 1: "Using 360-degree videos and VR are more useful than traditional learning methods" (from 560 survey respondents, $\mathrm{n}=560$ )

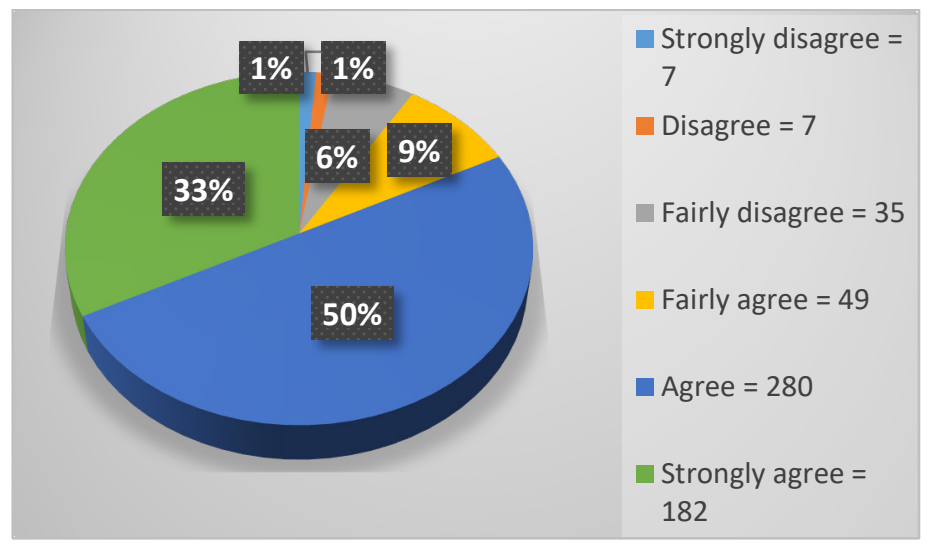

The greatest strengths of 360-degree videos and virtual reality (VR) experiences lie in their abilities not just to make the learning more immersive and interactive, but also to allow learners or endusers to gain access to limitless exposure time to specific learning materials, be it for the teaching of languages or any other tertiary level subjects. Indeed, 360-degree videos and VR allow learners to learn as much as they want, when they want to; the more time a learner spends being immersed in these technologies, the more 
prepared she or he will be for formal assessments and other tests related to the language courses her or she is taking. This fact is not lost on the respondents as shown in Graph 2.

Graph 2: "Using 360-degree videos and VR I can get more time to practice before facing tests" (from 560 survey respondents, $\mathrm{n}=560$ )

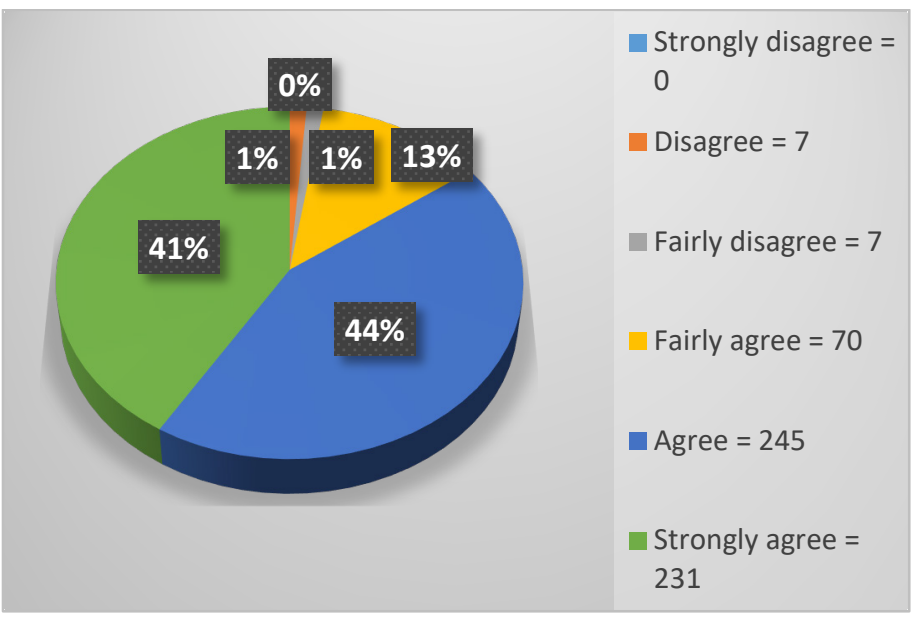

Graph 2 above is a clear indicator of the usefulness and utility of 360-degree videos and also VR experiences in terms of helping learners to practice intensively and extensively before they face course assessments or tests. However, bear in mind that these statements relate mainly to the teaching and learning of English Language, Mandarin Chinese, and Arabic Language. And so, it is quite surprising to find that the respondents were equally open to the idea of using 360-degree videos and VR experiences for the teaching and learning of other subjects at university level, as shown in Graph 3 below.

Graph 3: "360-degree videos and VR experiences should be introduced for other university subjects" (from 560 survey respondents, $\mathrm{n}=560$ )

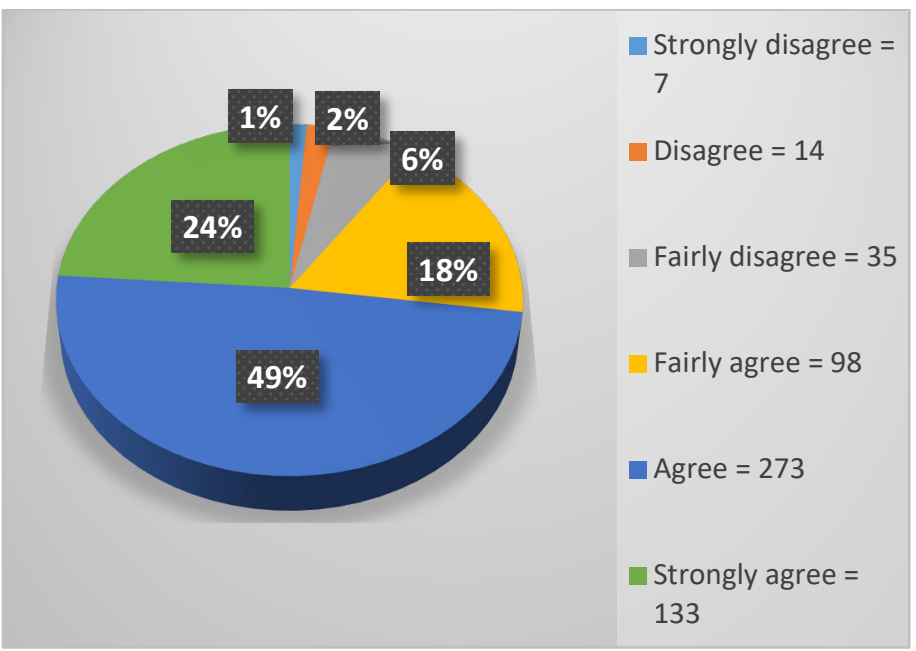

Interestingly, the respondents also showed very positive orientation towards the use of 360-degree videos and VR experiences at university level not just for individual subjects or courses. They believe that the administration of the universities should apply these technologies for future teaching and learning initiatives, so that other students too can benefit from immersive and interactive learning technologies. The responses recorded are presented in Graph 4, next.
Graph 4: "In future, my university should use more technologies like 360-degree videos and VR" (from 560 survey respondents, $\mathrm{n}=560$ )

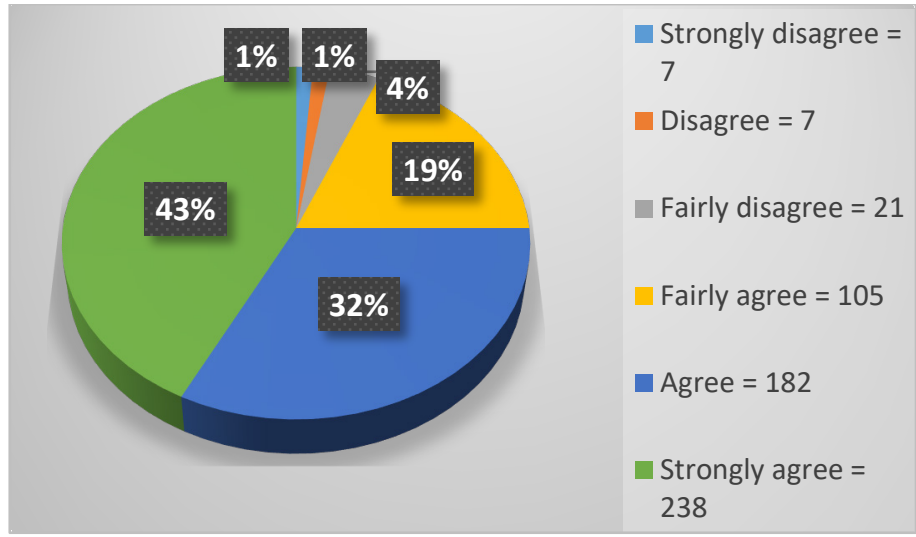

In another survey item related to Graph 4, the respondents were asked whether their lecturers should be more open to the idea of using 360-degree videos and VR experiences in the teaching and learning process as shown in Graph 5. This is because one of the biggest obstacles in the adoption of $21 \mathrm{st}$ century learning technologies is the disinterestedness of tertiary lecturers and course instructors. Perhaps these lecturers and instructors feel that traditional methods are still needed or maybe they think that teaching and learning with technology is an unneeded hassle within their campuses. Without a doubt, these data must be used to inform future empirical studies that examine the roles of tertiary lecturers and instructors as content developers for future learning initiatives.

Graph 5: "The lecturers at this university need to be open to 360-degree videos and VR experiences" (from 560 survey respondents, $\mathrm{n}=560$ )

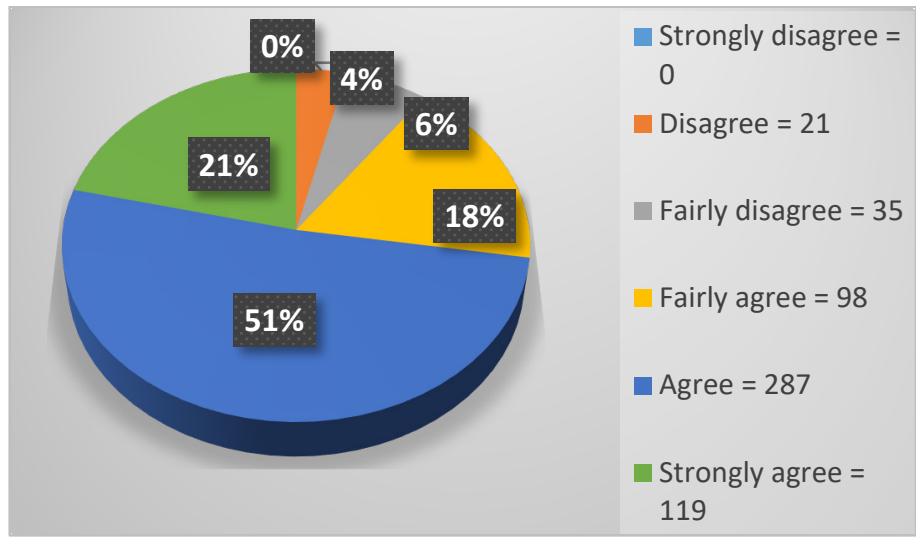

Items 15 and 16 in the survey questionnaire are related to the technical side of the deployment of 360-degree videos and VR experiences in the teaching and learning dyad. Even though learners can interact with 360-degree videos using YouTube, in the form of spherical or 360-degree video objects, to truly become immersed in the learning process they need to invest in VR goggles. There are many types of VR goggles that can be procured but the cheapest and most accessible, especially for university students, seem to be the VR goggles that are powered by their own smartphones. Users need only mount their smartphones within the goggles to access interactive and immersive VR experiences.

Higher immersion leads to a better engagement with the subject matter at hand, in this case the English Language, Mandarin 
Chinese, or Arabic Language. Higher immersion and the ability to interact with VR experiences also lead to more exposure time which can help with the acquisition and practice of specific skills. Graph 6 shows that many of the respondents were interested in buying VR goggles as part of their learning process at university.

Graph 6: "I think VR goggles are a good investment if used for teaching and learning at university" (from 560 survey respondents, $\mathrm{n}=560$ )

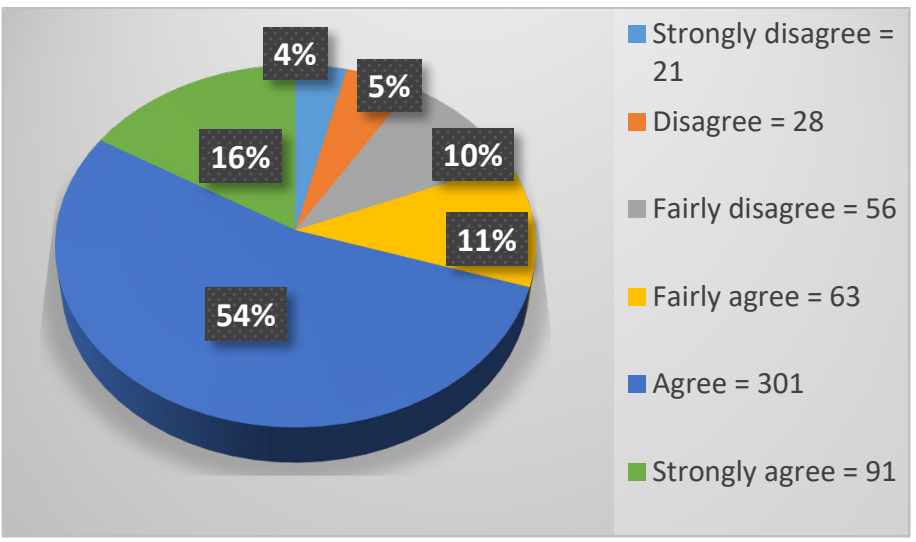

It must also be stated that although the respondents generally harbour positive views on the use of 360-degree videos and VR experiences in the teaching and learning process, there are several technical obstacles that hinder the wider adoption of these teaching and learning technologies. Understandably, it must be frustrating for university students to have to contend with mobile data limits and bad Internet connectivity when they want to use 360-degree videos and VR experiences to learn new things and to practice new skills. That being said, these annoying issues seem to plague and to hinder a wider use of Internet-related teaching and learning technologies at this present moment, in Malaysia and in most developing countries. Graph 7 portrays the frustrations of the respondents.

Graph 7: "360-degree videos and VR experiences are cool, but the problem is that our Internet sucks" (from 560 survey respondents, $n=560$ )

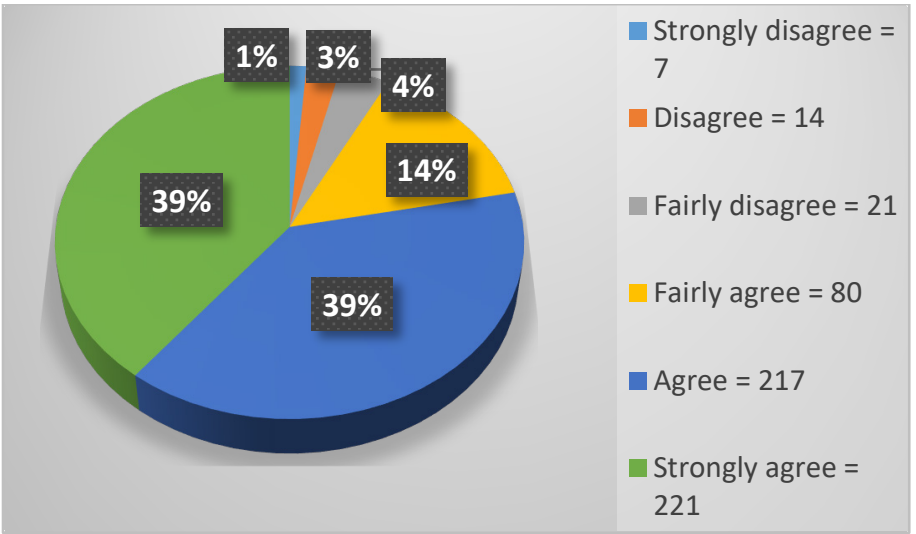

The final graph, Graph 8, is a clear indication that Malaysia as a developing nation is moving in the right direction in terms of deploying 360-degree videos and VR experiences in the teaching and learning process at university level. Only 119 respondents or $21.25 \%$ of the population under study have somewhat negative feelings in terms of the contribution of these technologies to their skills and knowledge (in the English Language, Mandarin Chinese, or Arabic Language) compared to 441 respondents or $78.75 \%$ who have accepted these technologies in a positive light. In other words, for every five undergraduates at university, four will benefit from the use of 360-degree videos and VR experiences in the teaching and learning process.

Graph 8: "Contribution to learning (VR 360-degree videos and VR experiences) to my level of skill/knowledge at the END of my course in either English or

Mandarin or Arabic languages" (from 560 survey respondents, $n=560$ )

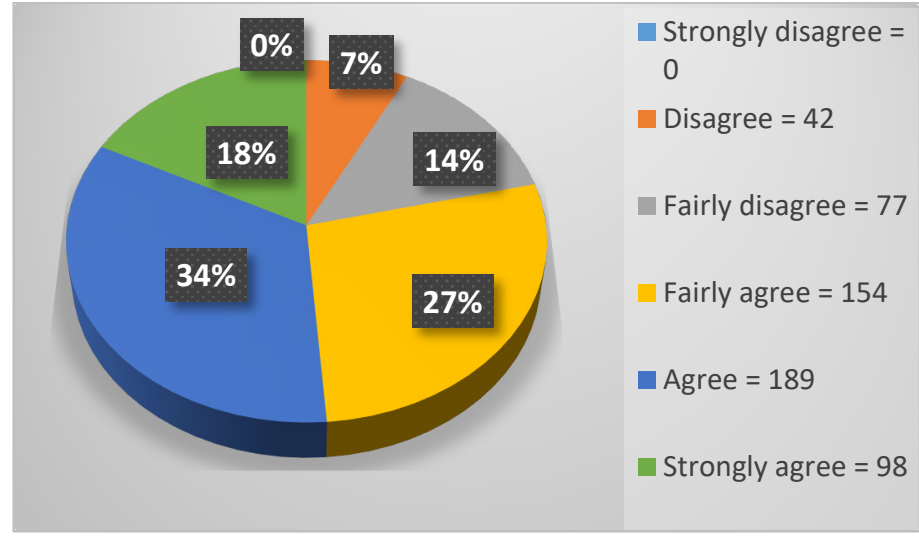

\subsection{Cycle 2: Textual/qualitative data}

Cycle Two of the data collection and analysis process relied on focus group discussions to gain insights into the ideas, feelings and opinions of the participants with regards to the use of 360-degree videos and VR. These focus group discussions were linked with the post-evaluation of test performances for the students involved in the English Language, Mandarin Chinese, or Arabic Language courses.

Five open questions were then posed to a group of four to five participants regarding the same subject matters covered in Cycle One. The names below are pseudonyms chosen by the participants to protect their identities but the comments shared are actual comments and utterances with only minor editing to improve accuracy and to follow academic writing conventions.

\subsubsection{Benefits and advantages of VR experiences and 360-degree videos at university}

According to 'Siti Noorul Nadiah', "Technology that uses 3dimensional graphics makes us, the users, feel like we are really interacting in the real world. We can also visualise abstract learning materials, so these materials become easier to understand, more enjoyable and fun to learn." Siti's ideas and feelings seem to be shared by nearly all the participants, due to the fact that they have all been exposed to VR experiences and 360-degree videos.

For 'Nurul Ainal Ainaa,' the biggest benefit of using VR experiences and 360-degree videos in the teaching and learning process is the exposure to new technologies that are relevant in the era of Industry 4.0. She further explained:

Technology like this is really quite expensive to buy or develop. So, when we use this in class, students can have the opportunity to learn using the state-of-the-art VR technology and 360-degree videos. My friends and I also noticed that the learning process can be a lot more interesting and fun by using VR and 360-degree videos, but the problem right now is that our lecturer doesn't have much materials to teach us with this advanced technology. 
4.2.2. Problems faced when using VR experiences and 360-degree videos at university

Echoing Nurul's last sentence, 'Che Mamat' said, "I feel there should be many more things (contents) using VR and 360-degree videos but I also understand they're not easy to create. Maybe if there are more courses using VR, more students can learn using this technology." Another challenge for university students when they use technologically-enhanced learning materials is related to technical issues. Problems linked to limited access to mobile Internet data and stability issues when they use public networks on campus, commonly lead to audio loss, video stutter and other technical annoyance that lessen the overall quality of their immersive VR experience. In all fairness, these issues are not just annoying, but they could hinder the wider acceptance and use of technologies like VR experiences and 360-degree videos in the long run. In the words of 'Ahmad Afnan':

Other than the connection problems, the most common problem at this time is that not all students have VR goggles, so it's quite complicated to watch the videos because I need to make the phone stable to focus at the best point, and I need to scroll the screen to see the whole video all the time. This takes a lot of my time and sometimes I lose the key points in the VR videos. Next, the sound is slow. Although, I am using earphones with the highest volume I cannot hear clearly... Our lecturer must create VR with higher quality in future.

4.2.3. Feelings after being chosen to test VR experiences and 360degree videos for the different second or third (foreign) language courses

On the whole, all of the participants were appreciative in being given the chance to test and use VR experiences and 360-degree videos for their English Language, Mandarin Chinese, or Arabic Language courses. They particularly love the opportunity to try out the technology, the chance to get more exposure to key skills in their course and the chance to learn in a modern way that is totally different from the traditional methods that they are used to. As 'Siti Zaleha' observed:

This semester I was exposed to new technology and I learned about the professional worker of the future. For English, in class, we don't just learn about English, but the lecturer also teaches about how to use $360^{\circ}$ Degrees (videos) and Virtual Reality out of class using our own initiatives. As students we will become more advanced in technology and I think this style is an effective learning method, similar to the 21 st century learning concept. I think we need more chances to learn in this method even for the other subjects and courses.

4.2.4. Improvements needed to make VR experiences and 360degree videos more useful

Many participants commented about the overall 'production value' of the 360-degree virtual reality experiences that needs to be improved, if the project is planned for a wider dissemination and use in the future. They were particularly annoyed with the low sound quality of the VR experiences even though they feel that the videos are of sufficiently high quality. The fact that these VR experiences and 360-degree videos were prepared for English Language, Mandarin Chinese, or Arabic Language courses where communication skills are tantamount to success makes this a thoroughly valid point. As 'Zachary' mentions, "Another way is you should probably put subtitles to support the audio of the video because I couldn't really hear well. Also, everyone's pronunciations are different so subtitles will come in handy." Another enlightening comment was made by 'Nurain Ahmed':

Maybe the video doesn't have to be related to lectures all the time? I mean maybe, the lecturer can also do online question and answer sessions from time to time or maybe we play online question games, so that students can enjoy the class more. The online games and online quizzes can test their grammar or vocabulary for the professional workplace, maybe? Students will definitely feel more excited to do these things because the class will feel more relaxed. Then, we can just revise on our own using VR after the class time.

\subsubsection{Whether the participants support (or not) a wider deployment of VR and 360-degree videos}

From the 560 respondents / participants involved in this study, 553 or an impressive $98.75 \%$ supports the use of VR experiences and 360-degree videos for teaching and learning at university. Just seven participants or $1.25 \%$ does not support the wider deployment of these Education 4.0 learning technologies. For 'Siti Zafirah', she is against the use of these technologies for two reasons. First, the network access to the Internet on campus is very bad. And second, she feels that she has no choice but to buy the VR goggles. 'Ahmad El-Zickry' also disagrees with any initiatives to widen the use of VR and 360-degree videos:

I strongly disagree with VR-360 technology because it requires strong Internet connection. However, as you know in this campus the Internet connection is very weak and too slow for learning. When I use the VR and 360-degree videos, it turns out to be someone else talking but someone else's face had come out. What kind of learning is this? This is rubbish!

For the majority of the respondents, they believe that VR experiences and 360-degree videos represent the future of teaching and learning in Malaysia. They, therefore, support these technological initiatives even though they too face some difficulties related to Internet connection and not having access to VR goggles. 'Alia Ibni Bakar' shared her insights on this matter:

I agree totally with the usage of the VR and 360-degree videos. It's time to change our teaching and learning style. This is a new road that our university must take if they want to use this teaching style. Some of us students, we also want to experience new things while we're still studying. So, I think this new method of learning and teaching is good for students like myself. Maybe by using this method, students will feel more excited to learn difficult subjects and it will be easy for them to revise subjects? All we have to do is just replay and replay stuff.

\section{Conclusion}

There are barriers to the wider adoption of Education 4.0 learning technologies at university level in Malaysia [21]. These barriers are mostly related to technical issues, like patchy connections to the Internet and limited materials available that take advantage of the VR experiences and 360-degree videos in delivering quality educational contents. That being said, these 
barriers should not stop Malaysian university lecturers and instructors from becoming learning technologists who strive to make learner-driven learning a reality. In truth, technological tools, development software and related apps are now easily available in the mainstream consumer market that allow for the creation and development of cutting-edge teaching and learning materials. In addition, the boom in Industry 4.0 manufacturing has brought down the prices of these tools, software and apps, making them more affordable for self-funded university educators to start their own teaching and learning innovation projects.

This empirical study contributes to the literature on education, and teaching and learning for year 2020 and beyond, looking specifically at VR experiences and 360-degree videos to deliver quality educational contents to teach specific (and difficult) skills in the English Language, Mandarin Chinese, and Arabic Language courses at four different public university campuses in a developing country. Employing 360-degree spherical video cameras and software that can record, render and playback immersive real-life contents, these contents can then be postprocessed into VR experiences that are not just immersive but offer limitless opportunities for learning exposure, as depicted in Figure 1 at the start of this empirical paper.

Both technologies allow for learner-driven learning to happen, for a group of 560 second and some third (foreign) learners at four different public university campuses in Malaysia. The results are extremely encouraging, as seen in the numerical and textual data records presented in this paper. Immersion followed by further repeated exposure has helped the learners (end-users) to acquire the specific skills that they need and to practice for course-related assessments even with limited classroom contact hours. With these concrete data, it is possible to imagine that VR experiences, 360-degree videos and other Education 4.0 teaching and learning technologies will soon move into the mainstream and bring true the learner-driven 21 st century learning to university classrooms in Malaysia and in other developing nations around the globe.

\section{Conflict of Interest}

The authors declare no conflict of interest.

\section{Acknowledgement}

The corresponding author would like to thank his colleagues at all research sites for their willingness to try out 360-degrees video technology and virtual reality or VR technologies that he had developed for the teaching and learning of second and third (foreign) language courses (at their respective university campuses in Peninsular Malaysia). The corresponding author also acknowledges the assistance of Mr. Muhamad Khairul, Mr. Muhammad Anwar, Miss Nurul Nadiah and Mr. Ahmad Ariffuddin, young short-term contract lecturers from his Future Learning Initiatives Lab (FLI LAB @ UiTM), in helping to create and develop the 360-degrees video experiences. Special thanks to Mr. Mohamad Syafiq as the 'forensic proof reader' of this paper. It should be noted that this empirical project received no funding neither from the authors' institutions nor from the government of Malaysia; any and all costs incurred in the process of carrying out this academic project were borne by the authors/researchers ourselves.

\section{References}

[1] G. Leonhard, "As technology becomes cognitive, all paths must lead to collective human flourishing." https://www.forbes.com/sites/cognitiveworld /2019/02/25/as-technology-becomes-cognitive-all-paths-must-lead-to-collect ive-human-flourishing/, 2019.

[2] A. Davies, D. Fidler, M. Gorbis, Future Work Skills 2020. Palo Alto, CA, Institute for the Future, University of Phoenix Research Institute, 2011.

[3] K. Schwab, The Fourth Industrial Revolution. Geneva, World Economic Forum, 2016

[4] K. Schwab, N. Davis, Shaping the Fourth Industrial Revolution. Geneva, World Economic Forum. 2018

[5] World Economic Forum, The Future of Jobs: Employment, Skills and Workforce Strategy for the Fourth Industrial Revolution. Geneva, World Economic Forum, 2016.

[6] World Economic Forum, The Future of Jobs Report 2018. Geneva: World Economic Forum, 2018.

[7] U. D. Ehlers, S. A. Kellermann, Future Skills: The Future of Learning and Higher Education. Karlsruhe, International Future Skills Delphi Survey, 2019.

[8] A. H. M. Adnan, "Industry 4.0 skill sets, higher-order thinking skills and gamification: Lessons from 'Potentia Project', Malaysia" (Plenary Panel Presentation). Proceedings of TING X 2018: The Tenth National Meeting of Teachers 'Innovation in Education for Indonesia 4.0'. Tangerang: Universitas Terbuka Indonesia, 2018.

[9] AdvancED, "Learning in 3D: Making STEM Real." https://www.advanced.org/source/learning-3d-making-stem-real, 2015.

[10] 3DLabs (2019). "Virtual Reality and Augmented Reality." http://www.3dlabs.co.uk/virtual-reality/, 2019.

[11] A. H. M. Adnan, M. K. Ahmad, M. A. Mohd Kamal, N. N. Mustafa Kamal, A. M. Yusof, N. M. Azamri, "Virtual Reality Immersion for 'Education 4.0' English Education: ELSA $360^{\circ}$-Videos Project - Phase 2." In MNNF Publisher (Ed.), Leading Towards Creativity \& Innovation (Series 2) (pp. 329343). Senawang, MNNF Publisher, 2019.

[12] A. H. M. Adnan, M. K. Ahmad, A. A. Yusof, M. A. Mohd Kamal, N. N. Mustafa Kamal, "English Language Simulations Augmented with 360-degree spherical videos (ELSA 360-Videos): 'Virtual Reality' real life learning!' In MNNF Publisher (Ed.), Leading Towards Creativity \& Innovation (Series 1) (pp. 82-88). Senawang, MNNF Publisher, 2019.

[13] J. O. Wallgrün, A. Masrur, J. Zhao, A. Taylor, E. Knapp, J. S. K. Chang, A. Klippel, "Low-Cost VR Applications to Experience Real Word Places Anytime, Anywhere, and with Anyone." In 2019 IEEE 5th Workshop on Everyday Virtual Reality (WEVR) (pp. 1-6). IEEE, 2019.

[14] A. Doucet, J. Evers, E. Guerra, N. Lopez, M. Soskil, K. Timmers, Teaching in the Fourth Industrial Revolution: Standing at the Precipice. Oxford, Routledge, 2018.

[15] M. K. Ahmad, A. H. M. Adnan, A. A. Yusof, M. A. Mohd Kamal, N. N. Mustafa Kamal, "Using new technologies to teach English in Malaysia issues and challenges." In MNNF Network (Ed.), Proceedings of the Int'l Invention, Innovative \& Creative Conference, Series 1/2019 (pp. 203-207). Senawang: MNNF Network.

[16] Aniwaa, "The Ultimate VR, AR, MR Guide." https://www.aniwaa.com/ guide/vr-ar/ultimate-vr-ar-mr-guide/, 2019

[17] K. N. Mohd, A. H. M. Adnan, A. A. Yusof, M. K. Ahmad, M. A. Mohd Kamal, "Teaching Arabic Language to Malaysian University Students using Education Technologies based on Education 4.0 Principles." In MNNF Network (Ed.), Proceedings of the Int'l Invention, Innovative \& Creative Conference, Series 2/2019 (pp. 38-51). Senawang, MNNF Network, 2019.

[18] M. Rüfenacht, "Education 5.0 why we need to adjust the education system." https://medium.com/@MattiaSuisse/education-5-0-why-i-think-we-need-toadjust-the-education-system-4a669 b26396d, 2017.

[19] N. N. Mustafa Kamal, A. H. M. Adnan, A. A. Yusof, M. K. Ahmad, M. A. Mohd Kamal, “'Immersive Interactive Educational Experiences' - adopting Education 5.0, Industry 4.0 learning technologies for Malaysian universities." In MNNF Network (Ed.), Proceedings of the Int'l Invention, Innovative \& Creative Conference, Series 1/2019 (pp. 190-196). Senawang, MNNF Network, 2019

[20] P. Madigan, "A spotlight on virtual reality in the English classroom." mETAphor, 2, 56-58, 2018.

[21] A. H. M. Adnan, R. A. Karim, M. H. M. Tahir, N. N. Mustafa Kamal, A. M. Yusof, "Education 4.0 Technologies, Industry 4.0 Skills and the Teaching of English in Malaysian Tertiary Education." Arab World English Journal, 10(4), 330-343, 2019. DOI: https://dx.doi.org/10.24093/awej/vol10no4.24.

[22] R. A. Karim, A. G. B. Abu, A. H. M. Adnan, A. D. J. Suhandoko, "The Use of Mobile Technology in Promoting Education 4.0 for Higher Education." Advanced Journal of Technical and Vocational Education, 2(3), 34-39, 2018 DOI: https://dx.doi.org/10.26666/rmp.ajtve.2018.3.6. 
[23] J. Taplin, Move Fast and Break Things: How Facebook, Google, and Amazon Have Cornered Culture and What it Means for All of Us. London, Pan Books, 2017.

[24] Times Higher Education, "Preparing for Education 4.0." https://www.times highereducation.com/hub/jisc/p/preparing-education-40, 2019.

[25] A. H. M. Adnan, Z. M. Zamari, “'I am a Techno-Rebel!' Malaysian Academics $\&$ their Personal Experiences of Progressing into e-Learning." ProcediaSocial and Behavioral Sciences, 67, 61-72, 2012. DOI: https://doi.org/10. 1016/j.sbspro.2012.11.307.

[26] A. H. M. Adnan, "The use of, and attitudes toward, the English Language in Bumiputera Malay boarding schools in Malaysia: Reality of the Malaysian 'English language dilemma," Master of Arts Thesis, University of Leicester UK, 2001.

[27] C. Geertz, The Interpretation of Cultures: Selected Essays. New York, NY, Basic Books, 1973.

[28] C. A. Chapelle, P. A. Duff, "Some guidelines for conducting quantitative and qualitative research in TESOL.” TESOL Quarterly, 37(1), 157-178, 2003. 